\title{
The natural history of somatosensory and autonomic nerve dysfunction in relation to glycaemic control during the first 5 years after diagnosis of Type 1 (insulin-dependent) diabetes mellitus
}

\author{
D.Ziegler, P. Mayer, H. Mühlen and F. A. Gries \\ Diabetes Research Institute, Heinrich-Heine-University, Düsseldorf, FRG
}

\begin{abstract}
Summary. The natural evolution of neural dysfunction was studied prospectively over 5 years following diagnosis of Type 1 (insulin-dependent) diabetes in 32 patients aged 1236 years. Motor and sensory nerve conduction velocities, heart rate variation at rest and during deep breathing, and pupillary function were measured at diagnosis and after 3,12 , 24,48 , and 60 months. Thermal and vibration sensation thresholds were determined after 24,48 , and 60 months of diabetes. Mean $\mathrm{HbA}_{1}$ levels of months 3-60 within the normal range of $<8.3 \%(7.3 \pm 0.2 \%)$ were observed in $13 \mathrm{pa}-$ tients (Group 1), while a mean $\mathrm{HbA}_{1}$ of months $3-60 \geq 8.3 \%$ $(10.0 \pm 0.3 \%)$ was found in 19 patients (Group 2). Mean nerve conduction was significantly diminished in Group 2 as compared with Group 1 in at least 4 out of 6 nerves tested during months $12-60(p<0.05)$. Both tests of heart rate variation were significantly impaired in Group 2 as compared with Group 1 after 24 and 60 months $(p<0.05)$, but no differences in pupillary function were observed between the
\end{abstract}

groups. Thermal discrimination but not vibration perception thresholds on the foot were significantly higher in Group 2 than in Group 1 at 40 and 60 months $(p<0.05)$. Abnormalities in nerve conduction, thermal discrimination, and heart rate variation, but not vibration perception threshold and the pupillary function tests were significantly more frequent in Group 2 than in Group 1 at 60 months $(p<0.05)$. After 60 months, none of the patients of Group 1, but 6 and 4 patients of Group 2 developed subclinical or symptomatic neuropathy, respectively $(p<0.05)$. These findings suggest that the evolution of subclinical and symptomatic neuropathy during the first 5 years after diagnosis of Type 1 diabetes may be predicted by poor glycaemic control and prevented by near-normoglycaemia.

Key words: Diabetic neuropathy, glycaemic control, nerve conduction, autonomic function, sensory thresholds.
Polyneuropathy affecting the somatosensory and autonomic nervous systems is associated with an increased mortality in diabetic patients $[1,2]$. The role of glycaemic control in the development of prevention of diabetic neuropathy remains a matter or debate $[3,4]$. Considerable effort has been directed to beneficially influencing nerve function by restoring (near-)normoglycaemia using intensified insulin regimens $[5,6]$, continuous subcutaneous insulin infusion [5-8] or pancreatic transplantation [9]. However, the question of a possible primary prevention or a secondary amelioration of diabetic neuropathy has yet to be unequivocally answered $[3,4]$.

A wide spectrum of nerve function abnormalities including decreased motor and sensory nerve conduction [10-12], elevated thermal perception threshold [13], peripheral nerve ischaemia-resistance [14], diminished heart rate variation $[15,16]$, and impaired retinal [17] or pupil- lary neurophysiological function [11] have been described at the time of diabetes diagnosis. Some of these alterations are reversible within periods of up to 6 months following improvement of metabolic control [10, 17], whereas others remain unchanged $[12,14,15]$. However, there are no detailed studies that assess the evolution of neuropathy in relation to glycaemic control over several years following diagnosis of Type 1 diabetes.

This study was undertaken to evaluate whether the natural history of somatosensory and autonomic nerve dysfunction and possible clinically manifest neuropathy over the first 5 years after diagnosis of Type 1 diabetes is determined by the degree of glycaemic control. Furthermore, it was of particular interest to establish the onset of subclinical or symptomatic neuropathy and the pattern of involvement of the different fibre populations in relation to long-term glycaemic control. 
Table 1. Clinical characteristics of the patients at entry into the study

\begin{tabular}{lll}
\hline & $\begin{array}{l}\text { Group 1 } \\
\left(\mathrm{HbA}_{1}[\mathrm{mo} \mathrm{3}-\right.\end{array}$ & $\begin{array}{l}\text { Group 2 } \\
\left(\mathrm{HbA}_{1}[\mathrm{mo} \mathrm{3}-\right.\end{array}$ \\
\hline $\begin{array}{l}60]<8.3 \%) \\
\text { Number }\end{array}$ & 13 & 19 \\
Gender (M/F) & $10 / 3$ & $11 / 8$ \\
Age (years) & $20.3 \pm 0.9(16-25)$ & $20.7 \pm 1.5(12-36)$ \\
$\begin{array}{l}\text { Duration of symptoms } \\
\text { (weeks) }\end{array}$ & $3.9 \pm 0.9(1-11)$ & $5.6 \pm 2.4(1-20)$ \\
$\begin{array}{l}\text { Duration of insulin } \\
\text { treatment (weeks) }\end{array}$ & $2.9 \pm 0.5(1-6)$ & $2.2 \pm 0.4(1-9)$ \\
$\begin{array}{l}\text { Insulin dose (U/day) } \\
\text { HbA }\end{array}$ & $35.0 \pm 7.6(3-99)$ & $40.2 \pm 4.1(4-68)$ \\
$\begin{array}{l}\text { Mean blood glucose } \\
\text { (mmol/1) }\end{array}$ & $10.6 \pm 0.5(7.3-14.1)$ & $11.6 \pm 0.3(9.1-13.9)$ \\
$\begin{array}{l}\text { Fasting C-peptide } \\
\text { (ng/ml) }\end{array}$ & $6.1 \pm 0.4(4.7-8.2)$ & $6.9 \pm 0.2(4.7-8.7)$ \\
$\begin{array}{l}\text { Stimulated C-peptide } \\
\text { (ng/ml) }\end{array}$ & $1.1 \pm 0.4(0.2-1.8)$ & $0.8 \pm 0.2(0.2-1.3)$ \\
$\begin{array}{l}\text { Islet cell antibody } \\
\text { positive (\%) }\end{array}$ & $2.1 \pm 0.9(0.4-4.3)$ & $1.5 \pm 0.3(0.3-2.6)$ \\
\hline
\end{tabular}

Results given as mean \pm SEM (range)

\section{Subjects and methods}

\section{Patients}

Thirty-two of an initial cohort of 42 newly diagnosed Type 1 diabetic patients admitted to the metabolic ward of the diabetes Research Institute in 1985 [11] consented to participate in the study and were followed up for 5 years with visits on an outpatient basis at 3, 12,24, 48, and 60 months after the baseline assessment. Criteria for entry into the study included history of hyperglycaemia with or without ketonuria, requirement of insulin at the time of diagnosis of diabetes, age below 40 years, and absence of alcohol abuse, drugs known to influence somatosensory or autonomic nerve function, and neuropathies other than of diabetic origin. All subjects underwent a standardized one-week teaching programme including dietary instructions, training in self-monitoring of blood glucose, and learning about self-adjustment of the insulin dose.
To establish whether the natural history of diabetic neuropathy is related to the long-term quality of glycaemic control, the patients were grouped according to their mean $\mathrm{HbA}_{1}$ levels during the 5-year follow-up. Since in a group of 168 non-diabetic healthy subjects $\mathrm{HbA}_{1}$ was $6.4 \pm 0.6 \%$ (mean $\pm \mathrm{SD}$ ), the upper limit of normal for $\mathrm{HbA}_{1}$ was defined as $8.2 \%$, i.e. $3 \mathrm{SD}$ above the mean of the healthy population. Thus, patients with mean $\mathrm{HbA}_{1}$ levels of months $3-$ $60<8.3 \%$ were allocated to Group $1(n=13)$ representing subjects with long-term near-normoglycaemia, while those with mean $\mathrm{HbA}_{1}$ levels of months $3-60 \geq 8.3 \%$ were assigned to Group $2(n=19)$ representing subjects with long-term poor metabolic control. The clinical characteristics of both groups at entry into the study are shown in Table 1. There were no significant differences between the groups in regard to any of the parameters listed. The baseline assessment of nerve function was performed at mean blood glucose levels below $9 \mathrm{mmol} / \mathrm{l}$ in the absence of ketonuria for at least one week. None of the patients had clinical signs or symptoms of diabetic polyneuropathy.

Insulin therapy was initiated in all patients with either subcutaneous or intravenous application of human or porcine regular insulins. After correction of the initial metabolic derangement the patients were treated with 1 or 2 daily injections of either free mixtures of regular and NPH insulins or NPH insulin alone. After 5 years of study the number of patients treated with more than two injections per day increased from 0 to 7 in Group 1 and from 0 to 8 in Group 2, respectively.

The numbers of drop-outs from Group 1 and 2 were: 1 and 5 at 3 months; 0 and 2 at 12 months; 1 and 3 at 24 months; 0 and 1 at 48 months; and 2 and 3 at 60 months respectively. Table 2 shows the total number of test values obtained at the individual time points.

\section{Analytical methods}

Capillary blood glucose was determined using the hexokinase method (ACP 5040 autoanalyzer, Eppendorf, Hamburg, FRG). Mean blood glucose during the day of the baseline nerve function measurements was calculated as the mean of five values (fasting, postprandial, before lunch, before supper, and at bedtime).

Total glycosylated haemoglobin $\left(\mathrm{HbA}_{1} \mathrm{a}-\mathrm{c}\right)$ was measured at hospital admission and at $3,12,24,48$, and 60 months of study using the HPLC technique (Diamat, Bio-Rad, Munich, FRG). The mean \pm SD in bealthy subjects is $6.4 \pm 0.6 \%$.

Fasting and stimulated ( 7 min after $1 \mathrm{mg}$ glucagon i.v.) C-peptide was determined by radioimmunoassay (RIAmat C-peptide, BykMallinckrodt, Dietzenbach, FRG). The measuring range is between $0.3-30 \mathrm{ng} / \mathrm{ml}$.

Table 2. Numbers $(n)$ and percentages $(\%)$ of abnormalities and total numbers of values determined $(\Sigma)$ within subsets of identical or interrelated nerve functions

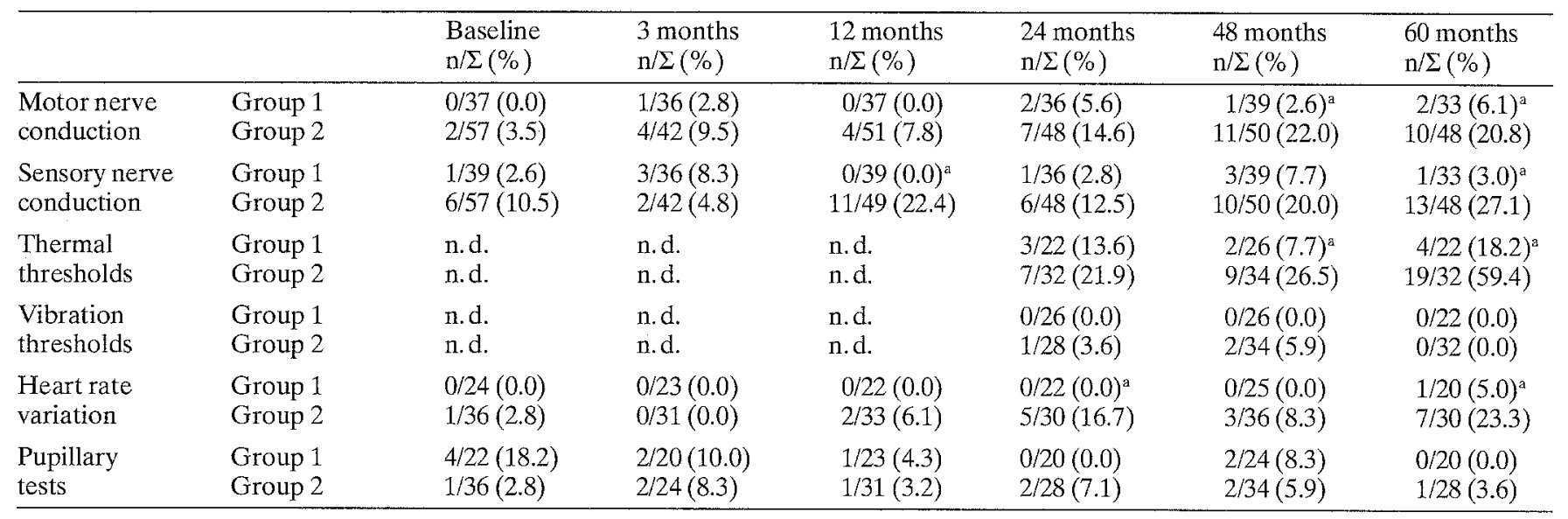

${ }^{\text {a }} p<0.05$ for Group 1 vs Group 2; n.d., not determined 
Islet cell antibodies were measured by indirect immunofluorescence using snap-frozen, unfixed human pancreatic sections of blood group 0 donors.

\section{Clinical evaluation}

Neurological examination at baseline and each visit included 1) reg istration of typical symptoms of polyneuropathy such as pain, paraesthesiae or numbness and 2) examination of tendon reflexes, muscle strength, and perception of pin pricks and joint position.

\section{Electrophysiological tests}

Nerve conduction studies were performed with an EMG 2000 electromyograph (Schwarzer-Picker, Munich, FRG) using surface electrodes. Motor nerve conduction velocity (MNCV) was measured in the right median, ulnar, and peroneal nerves and sensory nerve conduction velocity (SNCV) in the right median, ulnar, and sural nerves at local skin temperatures of $33-34^{\circ} \mathrm{C}$ as previously described [6]. Normal ranges were obtained from 60 healthy subjects aged $21-$ 64 years. MNCV and SNCV in both the median and ulnar nerves decreased significantly with increasing age $(p<0.05)$, while peroneal MNCV and sural SNCV were inversely related to height $(p<0.05)$. The lower limits of normal were derived from the following regression formulas representing the association of nerve conduction $(y)$, given in $\mathrm{m} / \mathrm{s}$, with either age $\left(x_{1}\right)$ given in years or height $\left(x_{2}\right)$ given in cm: median MNCV: $y=-0.14918 x_{1}+54.89$; ulnar MNCV: $y=-0.05527 x_{1}+54.39$; median SNCV: $y=-0.20349 x_{1}+56.79$; ulnar SNCV: $y=-0.18487 x_{1}+52.39$; peroneal MNCV: $y=-0.180 x_{2}$ $+75.22 ;$ and sural SNCV: $y=-0.158 x_{2}+71.98$

\section{Autonomic function tests}

The coefficient of variation of heart rate variability (HRV) was determined in the supine position at rest and during deep breathing using a microcomputer-based technique (Neurocard-Analyzer, Argustron, Mettmann, FRG) [18] as previously described [19]. Normal ranges were established in 120 healthy subjects aged 15-67 years. The lower limits of normal were defined according to the following equations representing the significant relation-ships between HRV (y) and age (x): HRV at rest (\%): $\log$ $y=-0.0073 x+0.680$ and HRV during deep breathing (\%): $\log$ $y=-0.0059 x+0.798$.

Infrared pupillometry was performed using a computer-based TV Pupillometer System, Series $1000(\mathrm{G}+\mathrm{W}$ Applied Science Laboratories, Waltham, Mass., USA) as previously published [19]. The computer calculated the pupillary dilation velocity and pupillary reflex latency. These indices were measured on each eye, and the results were expressed as the mean of both values. Normal values were determined in 106 and 100 healthy persons aged $20-63$ years, respectively. The following equations were used to define the age $(x)$ dependent lower limit of normal for pupillary dilation velocity $(y)$ given in $\mathrm{mm} / \mathrm{s}: y=-0.00785 x+0.752$ and the upper limit of normal for pupillary reflex latency $(y)$ given in ms: $y=0.829 x+384$.

Day-to-day reproducibility of the nerve function parameters mentioned above has been published elsewhere [19]. Nerve conduction and autonomic function tests were assessed at entry and after 3 , $12,24,48$, and 60 months of study.

\section{Cutaneous sensory thresholds}

Thermal discrimination threshold (TDT) was measured at 24, 48, and 60 months on the right thenar eminence and the lateral aspect of the dorsum of the foot using the Marstock stimulator [20]
(Somedic, Stockholm, Sweden) as previously described [21]. Normal ranges were established in 70 healthy volunteers aged 1764 years. The age $(x)$ dependent upper limit of normal for TDT $(y)$ on the foot given in $\Delta^{\circ} \mathrm{C}$ was defined by the equation $\log$ $y=0.004 x+0.702$. The normal range for the age-independent TDT on the thenar was $<3.0 \Delta^{\circ} \mathrm{C}$.

Vibration perception threshold (VPT) was determined at 24,48 , and 60 months on the right second metacarpal bone and medial malleolus using the vibrameter [22] (Somedic) as previously described [21]. Normal ranges were evaluated in 70 healthy subjects aged 20 64 years. The age $(x)$ dependent upper limit of normal for malleolar VPT (y) given in $\mu \mathrm{m}$ was defined by the formula $\log y=0.006 x$ -0.193 . The normal range for the age-independent metacarpal VPT was $<0.61 \mu \mathrm{m}$.

The 2.3rd and 97.7 th percentiles were used to define abnormality of both the age-dependent and age-independent nerve function parameters studied.

\section{Criteria for staging of neuropathy}

The following criteria were used for the definition of three stages of diabetic polyneuropathy: 1) reduced nerve conduction in two or more out of six nerves measured, 2) elevated TDT and/or VPT on the hand and/or foot, 3) diminished HRV under normal and/or deep breathing, 4) absent ankle/knee reflexes, decreased muscle strength and/or abnormal sensation, and 5) symptoms of neuropathy.

The stages of diabetic polyneuropathy were defined by an approach similar to the one proposed by Dyck [23]:

Stage 0 (no neuropathy): < two findings among criteria $1-4$ in the absence of neuropathic symptoms,

Stage 1 (asymptomatic = subclinical neuropathy): $\geq$ two findings among criteria 1-4 in the absence of symptoms,

Stage 2 (symptomatic neuropathy): $\geq$ two findings among criteria $1-4$ in the presence of symptoms.

\section{Statistical analysis}

All data showed normal distribution and were expressed by the arithmetic mean \pm SEM, except for TDT and VPT which showed log normal distribution and were expressed by the geometric mean $(\mathrm{GM}) \cdot \mathrm{SEF}^{ \pm 1}$ (SEF = standard error factor). The $t$-test for two independent samples was used to test differences between the groups. Qualitative data were given as relative frequencies and analysed by the chi-square test. Single linear regression analysis was used to study associations between variables. The paired $t$-test was applied to differences between the results at baseline and after 5 years.

\section{Results}

\section{Glycaemic control}

Mean $\mathrm{HbA}_{1}$ levels of months $3-60<8.3 \%$ were defined as long-term near normal glycaemic control. This range corresponds to the 99.7 th percentile, i.e. the mean $\mathrm{HbA}_{1}+3 \mathrm{SD}$ of healthy subjects. Patients with $\mathrm{HbA}_{1}$ of months $3-60<8.3 \%$ who achieved near-normoglycaemia constituted Group $1(n=13)$, while those with $\mathrm{HbA}_{1}$ of months $3-60 \geq 8.3 \%$ were considered poorly controlled and allocated to Group $2(n=19)$. Mean $\mathrm{HbA}_{1}$ was not significantly different between the groups at baseline (month 0 ), but at months 3-60 it was significantly higher in Group 2 as compared with Group 1 (all $p<0.05$ ) 


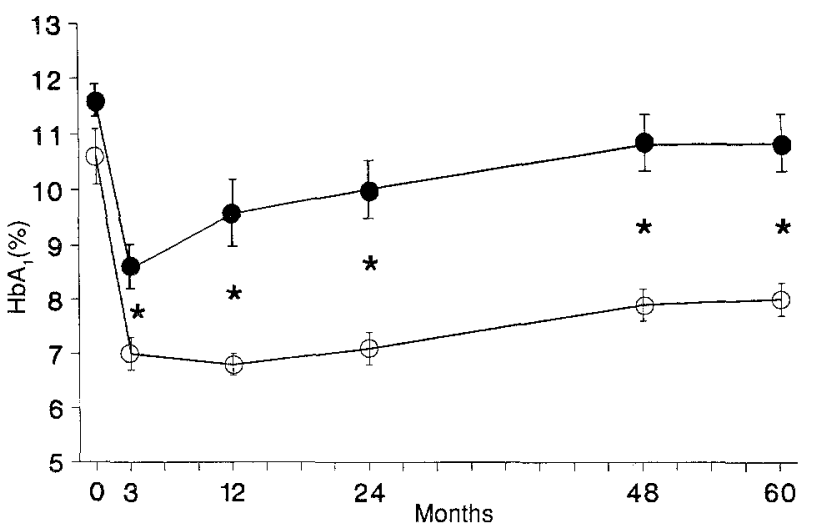

Fig. 1. Glycosylated haemoglobin $\left(\mathrm{HbA}_{1}\right)$ levels (mean $\pm \mathrm{SEM}$ ) in patients with mean $\mathrm{HbA}_{1}$ of months $3-60<8.3 \%$ (Group $1 ; n=13$ ) (O) and mean $\mathrm{HbA}_{1}$ of months $3-60 \geq 8.3 \%$ (Group $\left.2 ; n=19\right)(\bullet)$. $* p<0.05$ for Group 1 vs Group 2
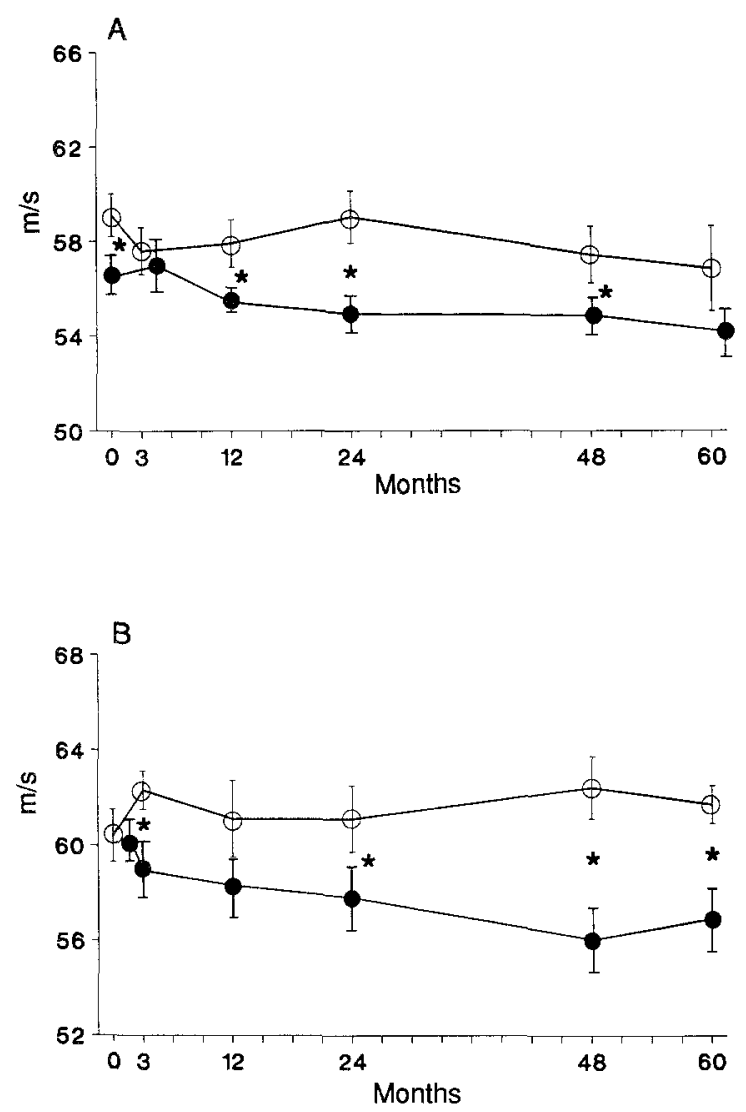

Fig. 2 A, B. Median A and ulnar $\mathbf{B}$ motor nerve conduction velocity (mean $\pm \mathrm{SEM})$ in Group $1\left(\mathrm{HbA}_{1}\left[\mathrm{mo}_{3}-60\right]<8.3 \% ; n=13\right)(\mathrm{O})$

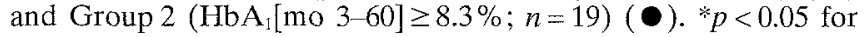
Group 1 vs Group 2

(Fig.1). Mean $\mathrm{HbA}_{1}$ levels of months 3-60 were $7.3 \pm 0.2 \%$ in Group 1 and $10.0 \pm 0.3 \%$ in Group 2 and remained remarkably stable during the study showing a uniform difference of $2.9 \%$ of $\mathrm{HbA}_{1}$ between the groups within months $12-60$. The mean insulin dose increased from $35.0 \pm 7.6 \mathrm{U} / \mathrm{day}$ at baseline to $49.3 \pm 7.6$ at 60 months in Group 1 and from $40.2 \pm 4.1$ to $59.2 \pm 4.2$ in Group 2.
Somatosensory and autonomic nerve function

The mean values of MNCV in the upper extremities are shown in Figure 2. Median MNCV was significantly decreased in Group 2 as compared with Group 1 at baseline, and 12,24 , and 48 months $(p<0.05)$ but not at months 3 and 60. Regarding ulnar MNCV there was no significant difference between the groups at baseline, but a significant decrease was observed in Group 2 as compared with Group 1 at each of the following visits $(p<0.05)$, month 12 excepted. No significant differences between the groups were noted for median and ulnar SNCV at baseline and after 3 months. However, during months 12-60, SNCV in both nerves was significantly diminished in Group 2 as compared with Group $1(p<0.05)$ (Fig. 3). The mean values for peroneal $\mathrm{MNCV}$ and sural SNCV were almost identical in both groups at baseline and 3 months. Thereafter they decreased in Group 2 compared to Group 1 reaching statistical significance in the sural nerve at 12,48 , and 60 months $(p<0.05)$ (Fig. 4$)$. The mean differences between both groups after 5 years were $3.1(1.8$ $4.8) \mathrm{m} / \mathrm{s}$ for MNCV and $3.5(3.2-3.8) \mathrm{m} / \mathrm{s}$ for SNCV.

The mean values of the coefficients of variation of HRV at rest and during deep breathing are illustrated in Figure 5. There were no significant differences between either group regarding HRV at rest during the first year of
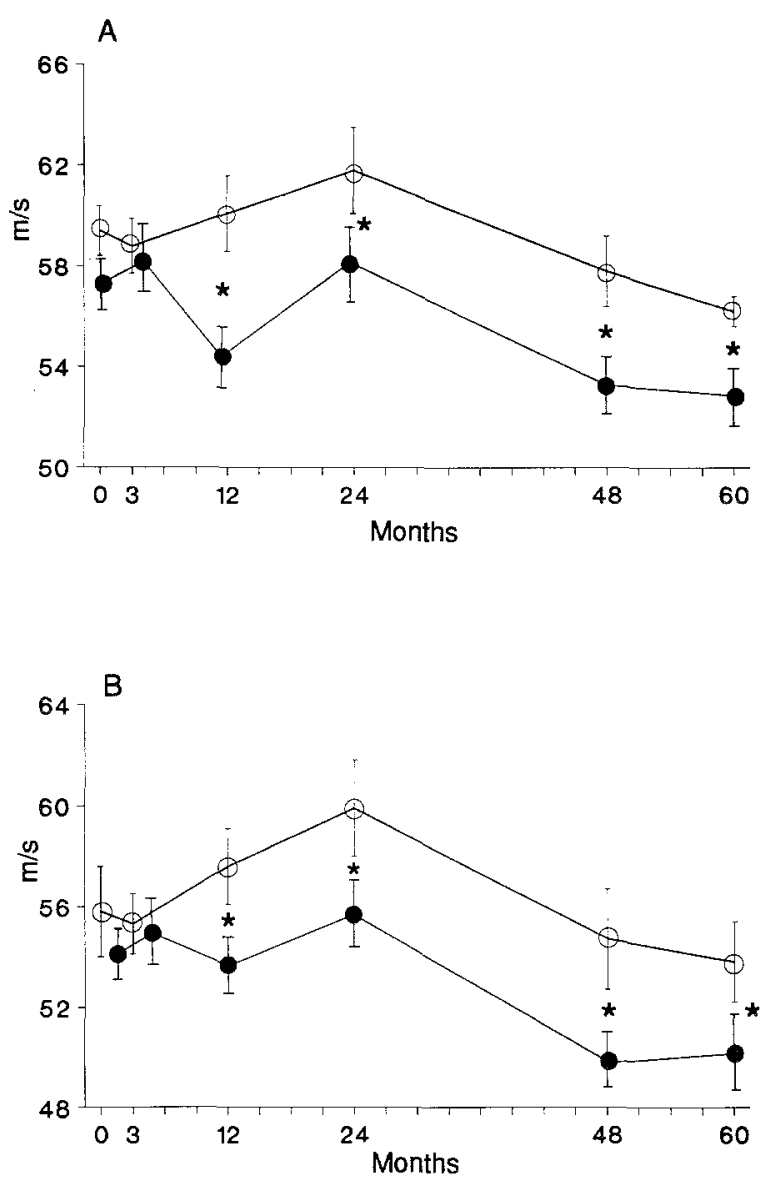

Fig. 3A, B. Median A und ulnar $\mathbf{B}$ sensory nerve conduction veloc-

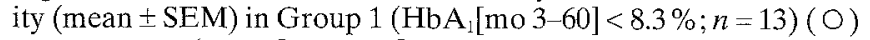
and Group $2\left(\mathrm{HbA}_{1}\left[\mathrm{mo}_{3}-60\right] \geq 8.3 \% ; n=19\right)(\bullet) . * p<0.05$ for Group 1 vs Group 2 

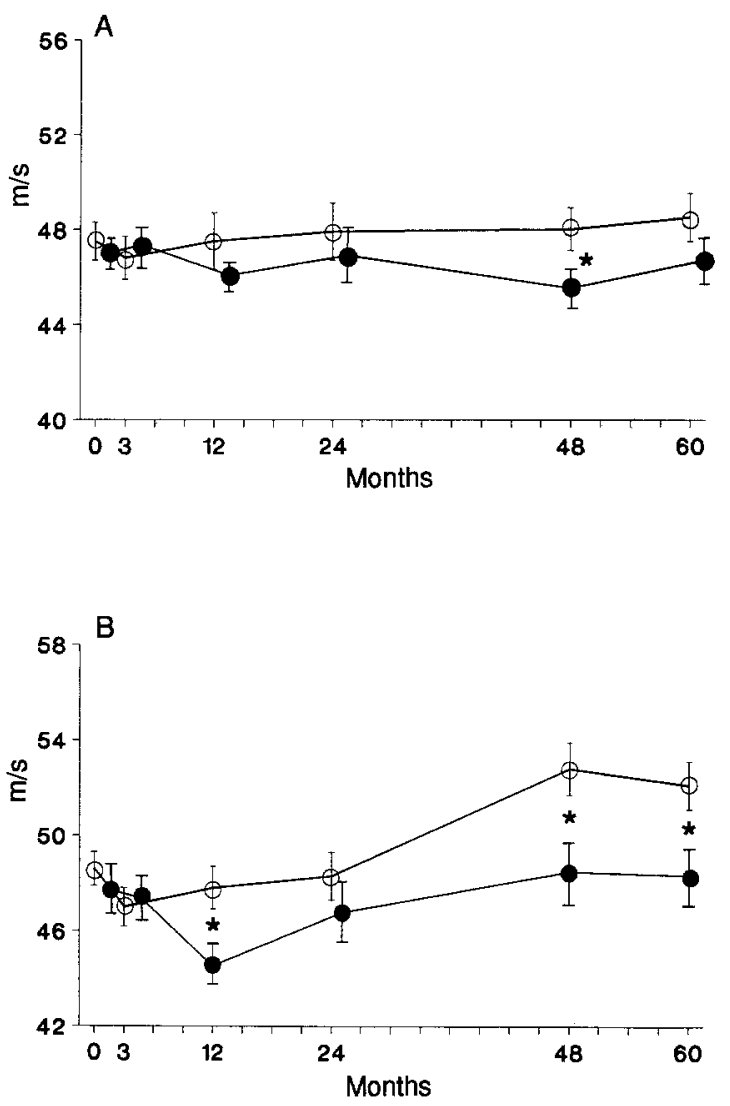

Fig. 4A, B. Peroneal motor $A$ and sural sensory $B$ nerve conduction velocity (mean $\pm \mathrm{SEM})$ in Group $1\left(\mathrm{HbA}_{1}\left[\mathrm{mo}_{3}-60\right]<8.3 \% ; n=13\right)$ (O) and Group $2\left(\mathrm{HbA}_{1}[\operatorname{mo} 3-60] \geq 8.3 \% ; n=19\right)(\bullet) . * p<0.05$ for Group 1 vs Group 2

study. However, during months $24-60, \mathrm{HRV}$ at rest was significantly diminished in Group 2 as compared to Group $1(p<0.05)$. Similar differences sustained during months 12-60 were observed for HRV during deep breathing $(p<0.05)$.

No significant differences between either group were detected in regard to the pupillary dilation velocity and pupillary reflex latency during the study, except for a prolongation of the latter at baseline in Group 1 as compared with Group $2(p<0.05)$.

Intraindividual analysis of the differences from baseline to 60 months yielded a significant increase in sural $\mathrm{SNCV}$, decrease in median SNCV, and shortening of pupillary latency in Group 1 (all $p<0.05$ ) and a significant slowing in ulnar MNCV and SNCV as well as median SNCV and shortening of pupillary latency in Group 2 (all $p<0.05)$. There were no significant differences over 5 years regarding the remaining tests.

The results of the quantitative tests of sensory thresholds after 2,4 , and 5 years of study are shown in Table 3 . Mean TDT on the thenar eminence was significantly elevated in Group 2 when compared with Group 1 at each testing $(p<0.05)$. There was no significant difference between the groups regarding TDT on the foot at 24 months, but after 48 and 60 months this parameter was significantly elevated in Group 2 as compared with Group 1 $(p<0.05)$. Malleolar and metacarpal VPT were signifi- cantly elevated in Group 2 when compared with Group 1 at 24 and 60 months, respectively $(p<0.05)$.

The number and percentage of abnormal test results within subsets of identical or interrelated functions, i. e. $\mathrm{MNCV}$ and SNCV in three nerves, respectively, TDT on the thenar and foot, metacarpal and malleolar VPT, HRV at rest and during deep breathing as well as pupillary dilation velocity and reflex latency are shown in Table 2. There were no significant differences between the groups regarding the percentage of MNCV abnormalities during the first 2 years. However, after 4 and 5 years the percentage of MNCV abnormalities increased significantly in Group 2 compared to Group 1, while for SNCV these differences were demonstrable after 1 and 5 years $(p<0.05)$. No significant differences after 2 years were noted regarding the percentage of abnormalities in TDT, but the latter were significantly more frequent after 4 and 5 years in Group 2 than in Group $1(p<0.05)$, whereas no such differences were demonstrable for VPT. Abnormalities in HRV were significantly more frequent in Group 2 than in Group 1 after 2 and 5 years $(p<0.05)$, but there were no differences between the groups regarding abnormalities in pupillary function.

The evolution of subclinical (stage 1) and symptomatic (stage 2) polyneuropathy within 2 to 5 years after diagnosis of Type 1 diabetes is shown in Table 4. All patients of
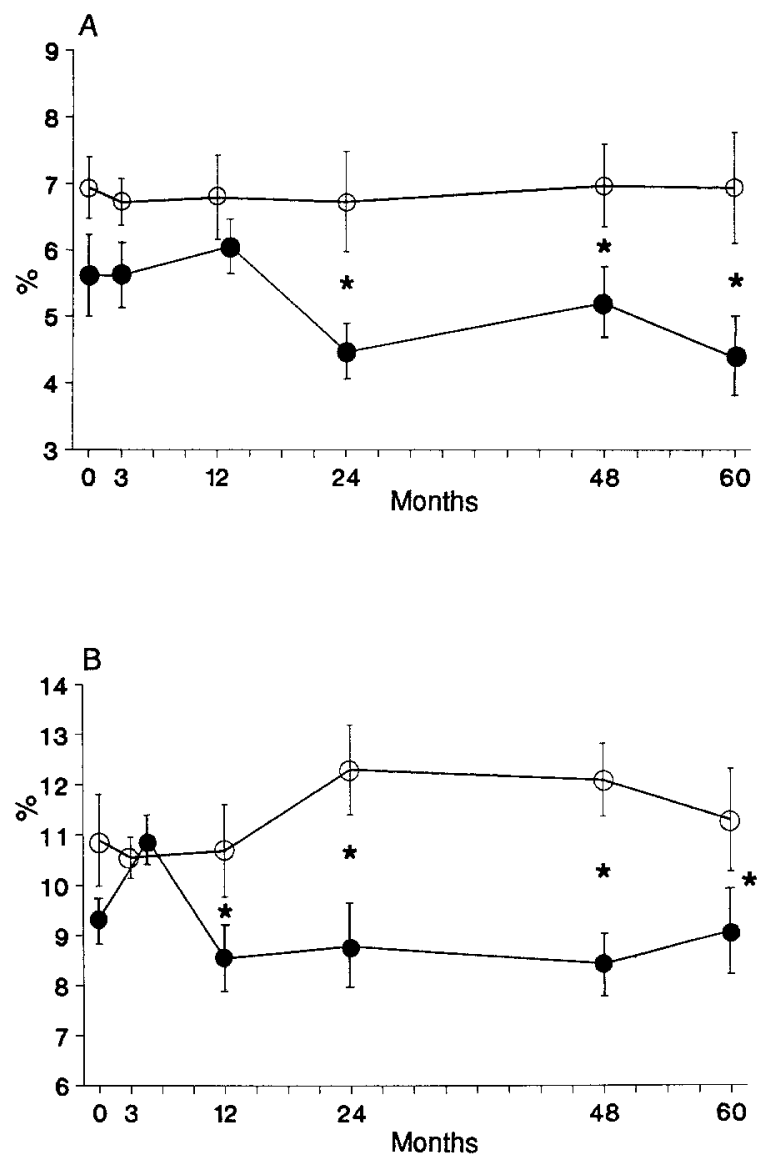

Fig.5A, B. Coefficient of variation of heart rate variability $\mathbf{A}$ at rest, B during deep breathing (mean $\pm \mathrm{SEM}$ ) in Group 1 ( $\mathrm{HbA}_{1}[\mathrm{mo}$ $360]<8.3 \% ; n=13)(\mathrm{O})$ and Group $2\left(\mathrm{HbA}_{1}\left[\mathrm{mo}_{3}-60\right] \geq 8.3 \%\right.$; $n=19)(\bullet) .{ }^{*} p<0.05$ for Group 1 vs Group 2 


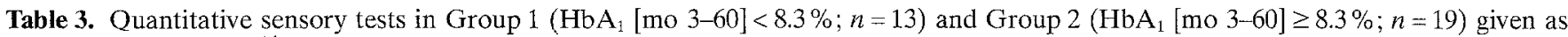
geometric mean $\cdot \mathrm{SEM}^{ \pm 1}$

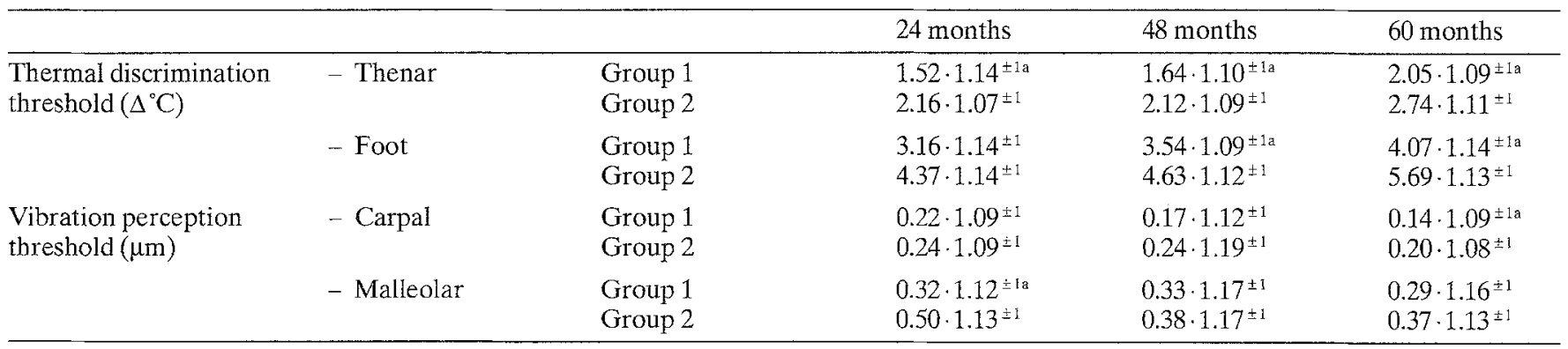

${ }^{\text {a }} p<0.05$ for Group 1 vs Group 2

Table 4. Number $(n)$ and percentage (\%) of patients with different stages of diabetic polyneuropathy (for definition of stages see methods)

\begin{tabular}{|c|c|c|c|c|c|}
\hline & & $\begin{array}{l}\text { Stage } 0 \\
n(\%)\end{array}$ & $\begin{array}{l}\text { Stage } 1 \\
n(\%)\end{array}$ & $\begin{array}{l}\text { Stage } 2 \\
n(\%)\end{array}$ & $\begin{array}{l}\text { Stage } 1+2 \\
n(\%)\end{array}$ \\
\hline 24 months: & $\begin{array}{l}\text { Group } 1(n=12) \\
\text { Group } 2(n=16)\end{array}$ & $\begin{array}{l}12(100) \\
14(87.5)\end{array}$ & $\begin{array}{l}0 \\
2(12.5)\end{array}$ & $\begin{array}{l}0 \\
0\end{array}$ & $\begin{array}{l}0 \\
2(12.5)\end{array}$ \\
\hline 60 months: & $\begin{array}{l}\text { Group 1 }(n=11) \\
\text { Group } 2(n=16)\end{array}$ & $\begin{array}{r}11(100)^{\mathrm{a}} \\
6(37.5)\end{array}$ & $\begin{array}{l}0^{\mathrm{a}} \\
6(37.5)\end{array}$ & $\begin{array}{l}0^{\mathrm{a}} \\
4(25.0)\end{array}$ & $\begin{array}{l}0^{\mathrm{a}} \\
10(62.5)\end{array}$ \\
\hline
\end{tabular}

${ }^{a} p<0.05$ for Group 1 vs Group 2

Group 1 were classified as having no neuropathy (stage 0 ) after 2,4 , and 5 years, respectively. In contrast, 6 patients of Group 2 developed subclinical neuropathy after 4 and 5 years $(p<0.05)$. Furthermore, 3 and 4 patients of Group 2 developed symptomatic neuropathy with paraesthesiae after 4 and 5 years respectively $(p<0.05$ at 5 years). Thus, ten $(62.5 \%$ ) patients of Group 2 , but none of Group 1 exhibited subclinical or symptomatic neuropathy after 5 years of Type 1 diabetes $(p<0.05)$. None of the patients studied developed decreased muscle strength or abnormal sensation as assessed by neurological examination. Three subjects of Group 2 but none of Group 1 developed absent ankle reflexes after 5 years.

There were no significant differences between the groups regarding the nicotine consumption during the study. The mean number of cigarettes smoked per day was $3.2 \pm 1.6$ and $3.8 \pm 2.0$ at 48 and 60 months in Group 1 and $9.7 \pm 3.5$ and $8.9 \pm 2.7$ in Group 2 , respectively $(p=0.11$ and $p=0.144$ ). The daily alcohol intake reported by the patients was negligible and did not differ between the groups.

\section{Discussion}

In this study we demonstrate that hyperglycaemia sustained over the first 5 years following diagnosis of Type 1 diabetes is a major determinant in the evolution of subclinical and symptomatic diabetic neuropathy, whereas the latter may be prevented by near-normoglycaemia. Furthermore, we show that indices of nerve conduction, thermal discrimination threshold, and heart rate variation provide sensitive measures to detect very early abnormalities and deterioration in nerve function in poorly controlled diabetic patients. In contrast, measurement of vibration perception threshold, and pupillary function are clearly less suitable for assessment of nerve dysfunction during the first 5 years of Type 1 diabetes. Since thermal discrimination thresholds were most frequently found to be abnormal among all nerve function parameters tested, it appears that dysfunction of small unmyelinated (C) and thinly myelinated $(A \delta)$ nerve fibres may precede that of large myelinated fibres. On the other hand the differences in the evolution of abnormalities of the various fibre populations could also be due to different sensitivities of the tests used.

Up to now there have been only two studies that assessed the natural history of nerve dysfunction in relation to glycaemic control over several years from the diagnosis of diabetes onward $[24,25]$. However, these studies have included either Type 2 diabetic patients [25] or subjects with both types of diabetes [24], have not relied on $\mathrm{HbA}_{1}$ as a measure of glycaemic control, and VPT was the only quantitative parameter for assessment of nerve function used. Pirart's study [24] has shown that the prevalence of neuropathy, defined as loss of tendon reflexes combined with reduced vibration sensation or presence of "a more dramatic polyneuropathy or mono- or multineuropathy", tended to increase in relation to the duration and severity of hyperglycaemia. Hillson et al. [25] have demonstrated that the deterioration in VPT within the first 5 years from diagnosis of Type 2 diabetes was associated with fasting hyperglycaemia. Since the present study did not provide evidence for such a deterioration, it is possible that the evolution of nerve dysfunction in Type 2 diabetic patients differs in some aspects from that in Type 1 diabetic patients. In fact, recent evidence suggests histopathological heterogeneity of neuropathy in Type 1 and Type 2 diabetic patients, i.e. primary axo-glial dysjunction in the 
former and Wallerian degeneration in the latter group [26]. Hence the natural history of nerve dysfunction described here is not comparable with that observed in the mentioned reports.

It cannot be derived from this study whether the demonstrated progressive decline in nerve function in poorly controlled patients reflects structural alteration. However, it has been shown that abnormalities in nerve conduction and thermal sensation thresholds are associated with fibre loss and abnormalities of the remaining fibres in the sural nerve in diabetic patients with and without neuropathy $[27,28]$. Hence, there is basis for speculation that the sustained slowing in nerve conduction observed in this study may reflect some early structural changes in the poorly controlled patients.

Previous studies in newly diagnosed diabetic subjects addressing the question of whether improved glycaemic control over periods of up to one year after starting insulin treatment may ameliorate initial nerve dysfunction, have shown controversial results. Motor nerve conduction and retinal neurophysiological function improved within 6 days to 6 months following diagnosis $[10,17,29]$, whereas sensory nerve conduction and heart rate variation remained unchanged after $6-12$ months of insulin treatment $[15,30]$. However, in most of these studies the baseline nerve function assessment was performed during ketotic or hyperglycaemic conditions [10, 15, 17, 29]. Hence, the results of these studies are not comparable with ours, because in this study the baseline nerve function measurements were carried out after treatment of initial ketosis and hyperglycaemia. Thus, nerve function abnormalities that are rapidly reversible within several days following the correction of metabolic derangement [31,32] did not contribute to the baseline test results.

To establish the natural evolution of nerve dysfunction in relation to the degree of glycaemic control, it was necessary to compare poorly controlled patients with those who achieved long-term near-normoglycaemia. The borderline $\mathrm{HbA}_{1}$ level was set at $8.2 \%$, i.e. $3 \mathrm{SD}$ above the mean $\mathrm{HbA}_{1}$ of healthy subjects. By this separation mean $\mathrm{HbA}_{1}$ levels of $10.0 \%$ and $7.3 \%$ during months $3-60$ of study were obtained in the poorly and well-controlled group, respectively. The observed difference of $2.7 \%$ of $\mathrm{HbA}_{1}$ was greater than the differences of $1.4-2.2 \%$ achieved in conventionally and intensively-treated patients in studies reporting the effects of near-normoglycaemia on nerve function [5-8] and in the Diabetes Control and Complications Trial [33]. Moreover, in the present study, long-term mean $\mathrm{HbA}_{2}$ in the group with near-normoglycaemia was within the upper limit of normal of $7.6 \%$, while it was above the normal range in the mentioned studies $[5,7,8,33]$. Although this study was not based on an experimental design, it is likely that the evolution of the marked differences in nerve function between both groups was due to the distinct and stable differences in glycaemic control. This suggestion is supported by the fact that confounding factors, which might have interfered with nerve function in this study, such as age, gender [34], degree of ketosis and $\mathrm{HbA}_{1}$ levels at diagnosis, alcohol intake, and smoking habit [35] were not significantly different between both groups.
The average differences in MNCV and SNCV between the strictly and poorly-controlled patients after 5 years of diabetes were 3.1 and $3.5 \mathrm{~m} / \mathrm{s}$, respectively. It has recently been reported that in prospective studies an average change of $2.3 \mathrm{~m} / \mathrm{s}$ represents a meaningful degree of prevention or improvement of $\mathrm{MNCV}$ in the median, ulnar, and peroneal nerves. The corresponding value for median SNCV was $1.9 \mathrm{~m} / \mathrm{s}$ [36]. These increases in nerve conduction may be associated with a clinically detectable improvement in the neurologic disability score [36]. Since the degree of prevention of the slowing in MNCV and SNCV observed in the present study exceeds the suggested changes, it may be clinically substantial. In poorly controlled Type 1 diabetic subjects with a mean duration of diabetes of 5 years, peroneal MNCV and sural SNCV but not HRV decreased significantly after an average follow-up of 2.5 years [37]. In contrast, we provide evidence that not only nerve conduction but also cardiovascular autonomic function and thermal sensation deteriorate within 2 years after diagnosis of Type 1 diabetes in poorly controlled patients as compared to those who achieved near-normoglycaemia. After 5 years not only subclinical neuropathy, but also the latter in conjunction with neuropathic symptoms have substantially developed only in poorly controlled patients. Thus, despite the relatively small number of patients studied, we show that the evolution of subclinical nerve function abnormalities during long-term hyperglycaemia seems to predict clinical neuropathy.

We conclude that hyperglycaemia is an essential determinant in the early natural evolution of somatosensory and cardiovascular autonomicnerve dysfunction and that nearnormoglycaemia maintained over the first five years following diagnosis of Type 1 diabetes may prevent this process. The results of the presentstudy provide a rationale for future long-term trials directed towards prevention of diabetic neuropathy by use of experimental drugs in poorly controlled, recently diagnosed Type 1 diabetic patients.

Acknowledgements. We thank Ms. M.Behler, Ms. H.Effertz-Umlauf, Ms. C. Gottschalk, and Ms. S. Witt for their excellent technical assistance, Dipl. Volksw. K. Dannehl for biometrical advice, Prof. H. Reinauer and his co-workers for the clinical chemistry measurements, Prof. H. Kolb for the ICA determinations, Dr. A. Hübinger for the C-peptide measurements, and Ms. C. Bergemann for expert secretarial assistance. This study was supported by grants from the Bundesminister für Jugend, Familie und Gesundheit and the Minister für Wissenschaft und Forschung, NRW.

\section{References}

1. Ewing DJ, Campbell IW, Clarke BF (1980) The natural history of diabetic autonomic neuropathy. Q J Med 49: 95-108

2. Navarro X, Kennedy WR, Loewenson RB, Sutherland DER (1990) Influence of pancreas transplantation on cardiorespiratory reflexes, nerve conduction, and mortality in diabetes mellitus. Diabetes 39: 802-806

3. Committee on Health Care Issues, American Neurological Association (1986) Does improved control of glycemia prevent or ameliorate diabetic polyneuropathy? Ann Neurol 19: 288-290

4. The DCCT Research Group (1988) Are continuing studies of metabolic control and microvascular complications in insulin-dependent diabetes mellitus justified? N Engl J Med 318: 246-250 
5. Dahl-Jorgensen K, Brinchmann-Hansen O, Hanssen KF et al. (1986) Effect of near normoglycaemia for two years on progression of early diabetic retinopathy, nephropathy, and neuropathy: the Oslo study. Br Med J 293: 1195-1199

6. Ziegler D, Wiefels K, DannehI K, Gries FA and the Düsseldorf Study Group (1988) Effects of one year of near-normoglycemia on peripheral nerve function in Type 1 (insulin-dependent) diabetic patients. Klin Wochenschr 66:388-396

7. Service FJ, Rizza RA, Daube JR, O’Brien PC, Dyck PJ (1985) Near normoglycaemia improved nerve conduction and vibration sensation in diabetic neuropathy. Diabetologia 28: 722-727

8. Jakobsen J, Christiansen JS, Kristoffersen I et al. (1988) Autonomic and somatosensory nerve function after 2 years of continuous subcutaneous insulin infusion in Type 1 diabetes. Diabetes 37: 452-455

9. Kennedy WR, Navarro X, Goetz FC, Sutherland DER, Najarian JS (1990) Effects of pancreatic transplantation on diabetic neuropathy. N Engl J Med 322: 1031-1037

10. Ward JC, Barnes CG, Fisher DJ, Jessop JD, Baker RWR (1971) Improvement in nerve conduction following treatment in newly diagnosed diabetics. Lancet I: 428-431

11. Ziegler D, Cicmir I, Mayer P, Wiefels K, Gries FA (1986) Peripheral and autonomic nerve dysfunction in newly diagnosed insulin-dependent diabetes. Transplant Proc 18: 1593-1594

12. Porte D, Graf RJ, Halter JB, Pfeifer MA, Halar E (1981) Diabetic neuropathy and plasma glucose control. Am J Med 70: 195-200

13. Ziegler D, Mayer P, Gries FA (1988) Evaluation of thermal, pain, and vibration sensation thresholds in newly diagnosed Type 1 diabetic patients. J Neurol Neurosurg Psychiat 51: 1420-1424

14. Newrick PG, Boulton AJM, Ward JD (1987) Nerve ischaemiaresistance: an early abnormalities in diabetes. Diabetic Med 4: $517-520$

15. Fraser DM, Campbell IW, Ewing DJ, Murray A, Neilson JMM, Clarke BF (1977) Peripheral and autonomic nerve function in newly diagnosed diabetes mellitus. Diabetes 26: 546-550

16. Lehtinen JM, Uusitupa M, Siitonen O, Pyörälä K (1989) Prevalence of neuropathy in newly diagnosed NIDDM and nondiabetic control subjects. Diabetes 38: 1307-1313

17. Frost-Larsen K, Sandahl Christiansen J, Parving H-H (1983) The effect of strict short-term metabolic control on retinal nervous system abnormalities in newly diagnosed Type 1 (insulin-dependent) diabetic patients. Diabetologia 24: 207-209

18. Morguet A, Springer HJ (1981) Microcomputer-based measurement of beat-to-beat intervals and analysis of heart rate variability. Med Progr Technol 8: 77-82

19. Ziegler D, Cicmir I, Wiefels K, Berger H, Gries FA (1987) Peripheral and autonomic nerve function in long-term insulindependent diabetes. Diab Res 4: 9-14

20. Fruhstorfer H, Lindblom U, Schmidt WG (1976) Method for quantitative estimation of thermal thresholds in patients. J Neurol Neurosurg Psychiatr 39: 1071-1075

21. Ziegler D, Mayer P, Wiefels K, Gries FA (1988) Assessment of small and large fiber function in long-term type 1 (insulin-dependent) diabetic patients with and without painful neuropathy. Pain 34: 1-10

22. Goldberg JM, Lindblom U (1979) Standardised method of determining vibratory perception thresholds for diagnosis and screening in neurological investigation. J Neurol Neurosurg Psychiatr 42: $793-803$
23. Dyck PJ (1988) Detection, characterization, and staging of polyneuropathy: assessed in diabetics. Muscle Nerve 11:21-32

24. Pirart J (1987) Diabetes mellitus and its degenerative complications: a prospective study of 4400 patients observed between 1947 and 1973. Diab Care 1: 168-188,252-263

25. Hillson RM, Hockaday TDR, Newton DJ (1984) Hyperglycaemia is one correlate of deterioration in vibration sense during the 5 years after diagnosis of Type 2 (non-insulin-dependent) diabetes. Diabetologia 26: 122-126

26. Sima AAF, Nathaniel V, Bril V, McEwen TAGJ, Greene DA (1988) Histopathological heterogeneity of neuropathy in insulindependent and non-insulin-dependent diabetes and demonstration of axo-glial dysjunction in human diabetic neuropathy. J Clin Invest $81: 349-364$

27. Dyck PJ, Karnes JL, Daube J, O'Brien P, Service FJ (1985) Clinical and neuropathological criteria for the diagnosis and staging of diabetic polyneuropathy. Brain 108: 861-880

28. Dyck PJ, Bushek W, Spring EM, Karnes JL, Litchy WJ, O'Brien PC, Service FJ (1987) Vibratory and cooling detection thresholds compared with other tests in diagnosing and staging diabetic neuropathy. Diab Care 10:432-440

29. Gregersen G (1968) Variations in motor conduction velocity produced by acute changes of the metabolic state in diabetic patients. Diabetologia 4:273-277

30. Comi G, Canal N, Lozza L et al. (1986) Peripheral nerve abnormalities in newly-diagnosed diabetic children. Acta Diabetol Lat 23: 69-75

31. Campbell IW, Fraser DM, Ewing DJ et al. (1976) Peripheral and autonomic nerve function in diabetic ketoacidosis. Lancet II: $167-169$

32. Troni W, Carta Q, Cantello R, Caselle MT, Rainero I (1984) Peripheral nerve function and metabolic control in diabetes mellitus. Ann Neurol 16: 178-183

33. DCCT Research Group (1990) Diabetes Control and Complications Trial. Update. Diab Care 13: 427-433

34. The DCCT Research Group (1988) Factors in development of diabetic neuropathy. Baseline analysis of neuropathy in feasibility phase of Diabetes Control and Complications Trial (DCCT). Diabetes 37: 476-481

35. Mitchell BD, Hawthorne VM, Vinik AI (1990) Cigarette smoking and neuropathy in diabetic patients. Diab Care 13: 434-437

36. Dyck PJ, O'Brien PC (1989) Meaningful degrees of prevention or improvement of nerve conduction in controlled clinical trials of diabetic neuropathy. Diab Care 12: 649-652

37. Young RJ, Macintyre CCA, Martyn CN et al. (1986) Progression of subclinical polyneuropathy in young patients with Type 1 (insulin-dependent) diabetes: associations with glycaemic control and microangiopathy (microvascular complications). Diabetologia 29: $156-161$

Received: 29 April 1991

and in revised form: 22 August 1991

Dr. D.Ziegler

Diabetes-Forschungsinstitut

an der Heinrich-Heine-Universität

Auf'm Hennekamp 65

W-4000 Düsseldorf 1

FRG 